\title{
Perancangan Destination Branding Desa Wisata Kerta di Kecamatan Payangan Kabupaten Gianyar
}

Eka Sita Michandani a,1 I Nyoman Sukma Arida a,2

1ekasita26@gmail.com 2sukma_arida@unud.ac.id

a Program Studi Sarjana Destinasi Pariwisata, Fakultas Pariwisata, Universitas Udayana, Jl. Dr. R. Goris, Denpasar, Bali 80232 Indonesia

\section{ABSTRACT}

This research was made to build a design of destination branding for Tourist Village Kerta in Payangan Districts, Gianyar Regency.

The Method that being used is qualitative description. The informant determination technique that being used are purposive sampling technique. The data sources that being used are secondary data sources and primary data sources. The Primary data on this report is a data that comes from the observation, focus group discussion (FGD) and interview. While the secondary data on this report comes from the documentation and literature study to completed the primary data.

The result from this research showing us that a brand from Tourist Village Kerta is a Climatic Village. Climatic Village was choosen as Tourist Village Kerta brand because Kerta Village has won many awards as Climatic Village. The logo design of Kerta Village as Climatic Village is described with four components such as a bamboo, a cow or a cattle, human and a temple. The bamboo, cattle and human was connected to the Tri Hita Karana concept, while the temple showing us the connection between human and the God.

Keywords: Destination Branding, Tourist Village Kerta, Climatic Village

\section{PENDAHULUAN}

Penetapan branding menjadi kendala bagi banyak produk yang akan dipasarkan. Dalam hal ini yang dimaksud produk adalah produk pariwisata berupa Desa Wisata. Banyak Desa Wisata yang belum mempunyai branding. Branding tersendiri merupakan hal penting bagi suatu Desa Wisata, karena branding bertujuan untuk menunjukkan identitas tempat tersebut. Dalam bidang pariwisata penetapan branding berpengaruh bagi suatu Desa Wisata. Disebabkan apabila penetapan branding tidak sesuai dengan karakteristik tempat tersebut maka akan menjadi boomerang bagi destinasi tersebut. Dalam hal ini diperlukan perencanaan mengenai destination branding agar bisa menarik wisatawan maupun menjadi alat komunikatif untuk mempromosikan tempat tersebut.

Bali yang merupakan tujuan utama pariwisata di Indonesia banyak memiliki desa wisata yang sudah banyak dikenal oleh wisatawan mancanegara maupun wisatawan domestik. Namun sayangnya belum adanya suatu branding yang bisa mengidentitaskan suatu desa wisata menyebabkan pengaruh besar terhadap kondisi desa wisata tersebut. Untuk itu diperlukan perencanaan destinastion branding supaya lebih mencirikan desa wisata tersebut. Desa Kerta ditetapkan menjadi Desa Wisata berdasarkan SK Bupati Nomor 429/E02/HK/2017 ini mulai dikembangkan menjadi desa wisata diperlukan pemberian destination branding untuk menjadi alat promosi desa wisata Kerta.

Desa Wisata Kerta memiliki banyak potensi wisata mulai dari potensi alam, potensi budaya dan potensi buatan. Desa Wisata Kerta ini termasuk dalam kriteria desa wisata sangat memenuhi. Ditinjau dari delapan aspek yakni aspek alam/bio hayati, lingkungan fisik, aspek budaya, aspek amenitas /prasarana, aspek sumber daya manusia, kelembagaan, sikap dan tata kehidupan masyarakat dan aksesbilitas (Arida dan Pujani, 2017). Namun promosi yang dilakukan Desa Wisata Kerta masih terbatas dari informasi mulut ke mulut. Hal tersebut memerlukan perhatian agar Desa Wisata Kerta lebih di kenal diantara banyaknya desa wisata yang ada di Kabupaten Gianyar. Dengan penetapan branding yang tepat Desa Wisata Kerta diharapkan bisa mendatangkan banyak wisatawan. Hal tersebut karena pengaruh branding menjadi alat promosi yang bisa menjual dan mempromosikan Desa Wisata Kerta. Untuk itu perancangan branding Desa Wisata Kerta harus di sesuaikan dengan kharakteristik desa tersebut sehingga menghasilkan branding 
yang sesuai dan menjadikan identitas Desa Wisata Kerta.

\section{TINJAUAN PUSTAKA}

\subsection{Telaah Hasil Penelitian Sebelumnya.}

Penelitian yang dilakukan oleh Hartanto dkk yang berjudul "Perancangan Destination Branding Desa Wisata Bermi Kabupaten Probolinggo", bahwa penelitian ini membahas mengenai proses merancang Destination Branding. Penelitian selanjutnya yakni dilakukan oleh Clarizza, dkk yang berjudul "Perancangan Destination Branding Wana Wisata Tanjung Papuma Kabupaten Jember", bahwa penelitian ini membahas mengenai sebuah brand pariwisata yang dimiliki setiap daya tarik wisata.

\subsection{Landasan Konsep}

Beberapa konsep yang digunakan dalam penelitian ini yaitu konsep potensi wisata (Marpaung, 2002), konsep destination branding (Kotler dan Keller, 2007), konsep perancangan (Hartanto, 2016), konsep kreatif (Hartanto, 2016).

\section{METODE}

Penelitian ini menggunakan metode kualitatif. Adapun jenis data yang digunakan dalam penelitian ini yakni data kuantitatif dan kualitatif. Sumber data yakni data primer dan sekunder. Data yang diperoleh dalam penelitian ini melalui teknik pengumpulan data observasi, Focus Group Discussion (FGD), wawancara dan studi dokumentasi. Teknik penentuan informan yang dipakai yakni metode Purposive sampling. Dimana Purposive Sampling itu sendiri merupakan metode dimana peneliti menetapkan lebih awal siapa saja yang menjadi informannya, dan menyebutkan status dari masing-masing informan sesuai dengan tujuan peneliti (Mukhtar, 2013).

1. Perbekel Desa Kerta, untuk memperoleh data mengenai kegiatan dan media promosi yang sudah dilakukan oleh Desa Wisata Kerta. Keunikan yang ada di Desa Kerta, positioning Desa Kerta, pengertian Desa Iklim, pengertian Bambu bun.

2. Ketua Badan Pengelola Desa Wisata, untuk memperoleh data mengenai keunikan yang ada di Desa Kerta.

3. Masyarakat yang diwakili oleh setiap kepala banjar yang ada di Desa Wisata
Kerta untuk memberikan usulan serta informasi dalam perancangan logo Desa Wisata Kerta melalui Focus Group Discussion (FGD).

\section{HASIL DAN PEMBAHASAN}

Desa Wisata Kerta merupakan satu dari sembilan desa yang ada diwilayah Kecamatan Payangan. Kecamatan Payangan sendiri merupakan salah satu dari tujuh kecamatan di Kabupaten Gianyar. Secara geografis Desa Kerta sendiri terletak diperbatasan sebelah barat Desa Buahan dan Buahan Kaja, utara Desa Banua dan Mangguh, timur Desa Taro, dan selatan berbatasan dengan Desa Puhu. Secara topografis Desa Kerta Kecamatan Payangan Kabupaten Gianyar merupakan daerah landau dan berbukit yang mempunyai ketinggian 650 s.d 950 meter diatas permukaan laut, dengan curah hujan $2200 \mathrm{~mm}$ pertahun. Adapun batas wilayah administratif sebagai berikut:

1. Sebelah Utara: Desa Banua dan Mangguh, Kintamani, Bangli.

2. Sebelah Timur: Desa Taro, Tegalalang, Gianyar.

3. Sebelah Selatan: Desa Puhu, Payangan, Gianyar.

4. Sebelah Utara: Desa Buahan dan Desa Buahan Kaja, Payangan

Desa Kerta terdiri dari delapan Banjar dengan potensi perangkatnya terdiri dari seorang Kepala Desa, seorang Sekretaris Desa (Sekdes), Tiga kepala Seksi (Kasi), Tiga Kepala Urusan (Kaur), dan delapan Kewilayahan/kelihan Banjar dinas/dusun serta delapan wilayah desa pakraman /adat ,yakni Banjar Dinas Kerta, Desa Pakraman Kerta, Banjar Dinas Penyabangan, Desa Pakraman Penyabangan, Banjar Dinas Mawang, Desa Pakraman Mawang, Banjar Dinas Margatengah, Desa Pakraman Marga Tengah, Banjar Dinas Seming , Desa Pakraman Seming, Banjar Dinas Pilan, Desa Pakraman Pilan, Banjar Dinas Saren, Desa Pakraman Saren, Banjar Dinas Bunteh, Desa Pakraman Bunteh .

Berdasarkan penggunaannya atau fungsinya luas wilayah desa Kerta, dipilah menjadi wilayah permukiman (pekarangan atau perumahan) seluas 33,55 hektar, persawahan seluas 177,25 hektar, tanah 
kering/ladang perkebunan seluas 845,09 hektar, areal hutan (hutan adat dan hutan rakyat) seluas 342,16 hektar dan fungsi lainlain (fasilitas umum, setra, jalan, pura, lapangan) seluas 27 hektar (Gunawan, 2016).

\subsection{POTENSI DESA WISATA KERTA}

Desa Kerta merupakan salah satu desa yang berada diujung utara Kabupaten Gianyar, memiliki potensi pariwisata yang cukup beragam baik potensi wisata alam, wisata budaya (heritage), maupun potensi buatan.

1. Potensi Alam. Desa Wisata Kerta memiliki banyak potensi alam meliputi flora, perkebunan dan pertanian Hortikultura, persawahan dan hutan.

2. Potensi wisata budaya (heritage) berupatradisi Bali Aga, Joged Pingit, Pura alas sangker, Pura Puncak Sari, situs goa dan sarkofagus.

3. Potensi Buatan. Desa Kerta, tidak hanya memiliki potensi alam dan potensi budaya adapun dari segi potensi buatan Desa Kerta memiliki Jembatan Kuning. Jembatan ini menghubungkan Banjar Penyabangan dan Banjar Pilan dengan panjang jembatan 64 meter dan lebarnya satu meter dan di bawahnya terdapat sungai. Ketinggian jembatan dari sungai mencapai 70 meter. Jembatan Kuning masih dalam tahap rekontrusi karena kondisi jembatan yang sudah rapuh karena dimakan usia. Jika telah terealisasi Jembatan Kuning sebagai atraksi wisata akan dikenakan retribusi ke wisatawan atau pengunjung yang datang. Diatas Jembatan Kuning pengunjung dapat melihat keindahan alam seperti hutan yang rindang dan ditemani kicauan burung yang memberikan kesan alami dan dapat dikembangkan sebagai atraksi wisata.

\subsection{PERANCANGAN DESTINATION BRANDING DESA WISATA KERTA}

Desa Kerta merupakan desa yang baru saja ditetapkan menjadi desa wisata sejak tahun 2017. Namun sudah mempunyai potensi wisata sejak dulu. Keberadaan Desa Wisata Kerta ini masih belum banyak dikenal oleh wisatawan. Desa Kerta mempunyai banyak potensi yang dapat menarik kunjungan wisatawan. Hal- hal yang menjadi keunggulan Desa Wisata Kerta tersebut belum diketahui masyarakat dan wisatawan secara umum, terutama destinasi branding Desa Wisata Kerta sendiri. Padahal destinasi branding sangat penting dalam persaingan pasar, dimana calon pembeli dihadapkan pada berbagai pilihan merek. Maka dari itu perlu ada perancangan destinasi branding Desa Wisata Kerta agar identitas dan citra Desa Kerta dapat dikenal baik oleh masyarakat dan wisatawan. Pembuatan perancangan sebuah destinasi branding diperlukan metode atau strategistrategi perancangan yang tepat dan efektif agar mencapai target sasaran. Untuk itu analisis konsep kreatif agar dapat mengetahui kegiatan dan media promosi, unique selling prepositio, positiong dan analisis target audiensi (Hartanto, 2016). Sedangkan analisis konsep perancangan untuk merancang desain logo berdasarkan citra visual yang ditampilkan dan unsur ikonik yang relevan. Konsep kreatif disini adalah cara untuk menyampaikan pesan dari perancangan identitas brand Desa Wisata Kerta melalui media komunikasi visual. Berbekal dari hasil data yang telah didapatkan, langkah selanjutnya adalah analisis kegiatan dan media promosi, positioning, unique selling preposition, dan analisis target audience (Hartanto, 2016). Dari analisis tersebut dapat disimpulkan konsep kreatif untuk perancangan brand Desa Wisata Kerta.

\section{Promosi}

Promosi yang dilakukan oleh Desa Wisata Kerta masih sangat minim. Disebabkan pengelola Desa Wisata Kerta masih belum siap jika datang wisatawan namun fasilitas yang tersedia belum memadai. Promosi hanya dilakukan dari mulut ke mulut. Belum adanya kegiatan untuk mempromosikan Desa Wisata Kerta. Seperti yang diungkapkan Perbekel Desa Kerta, Made Gunawan, pada wawancara hari Senin, 16 April 2018, dinyatakan bahwa

" kalau untuk promosi desa wisata masih belum di lakukan, promosinya cuma dari mulut ke mulut. Kita belum melakukan promosi karena kalau ada wisatawan yang datang dan ternyata fasilitasnya kurang memadai akan jelek nantinya di mata wisatawan"

Berdasarkan hal tersebut promosi Desa Wisata Kerta masih belum dilakukan karena ketersediaan dari fasilitas serta sarana penunjang sehingga pihak pengelola tidak ingin mengambil membuat wisatawan merasa 
kecewa setelah berkunjung ke Desa Wisata Kerta.

Media promosi yang digunakan untuk menunjukkan keberadaan Desa Wisata Kerta sangat jarang ditemukan. Papan petunjuk yang menunjukkan lokasi Desa Wisata Kerta berupa papan nama desa yang ukurannya tidak terlalu besar.

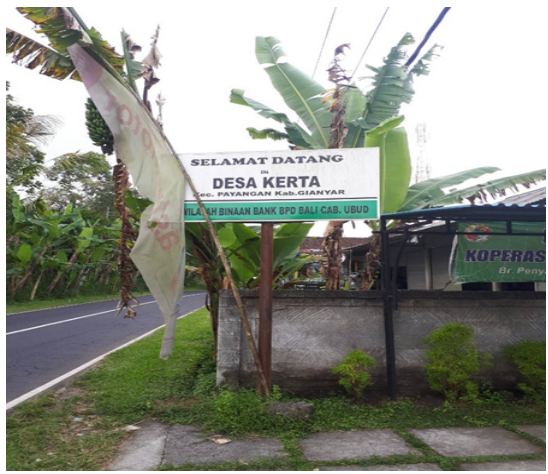

Gambar 4.1 Papan Desa Kerta Sumber: Hasil Penelitian, 2018

\section{Unique Selling Preprosition}

Unique Selling Preposition bertujuan membentuk karakteristik dari Desa Wisata Kerta. Desa Wisata Kerta sangat kental dengan nuansa perdesaannya mulai dari pertanian, perkebunan, hutan. Desa Kerta memiliki hutan seluas 342,16 hektar. Yang membuat udara di desa ini menjadi sejuk dan segar. Hutan tersebut terdiri dari hutan adat dan hutan rakyat. Hal ini menjadi bahan untuk pembuatan Branding Desa Wisata Kerta yang memunculkan keunikan nuansa perdesaan dari pertanian, perkebunan dan hutan.

\section{Positioning}

Positioning Desa Wisata Kerta yakni Desa Wisata Kerta sudah dikenal oleh masyarakat sebagai desa iklim, desa iklim yang dimaksud disini adalah kawasan hijaunya lebih luas dari pada kawasan non hijau. Kawasan hijau seperti hutan, pertanian dan perkebunan. Sedangkan kawasan non hijau adalah pemukiman warga dan fasilitas umum. Wilayah permukiman (pekarangan atau perumahan) seluas 33,55 hektar, persawahan seluas 177,25 hektar, tanah kering/ladang perkebunan seluas 845,09 hektar , areal hutan (hutan adat dan hutan rakyat) seluas 342,16 hektar dan fungsi lain-lain (fasilitas umum, setra, jalan,pura, lapangan dan sebagainya) seluas 27 hektar (Gunawan, 2016).
Kawasan Hijau = Luas Desa Kerta- Kawasan Non Hijau (permukiman + fasilitas umum)

$$
\begin{aligned}
& =1425.05-(33,55+27) \\
& =1425,05-60,55 \\
& =1364.5 \text { hektar }
\end{aligned}
$$

Jadi Desa Wisata Kerta dikenal sebagai Desa Iklim karena luas kawasan hijaunya sebesar 1364.5 hektar setelah dikurangi dengan kawasan non hijau nya. Desa Kerta sebelum ditetapkan menjadi Desa Wisata. Desa Kerta banyak mendapatkan penghargaan sebagai Desa Iklim. Yakni pada tahun 2011 dari Kementrian Kehutanan, tahun 2012 mendapat penghargaan sebagai Kampung iklim dan Desa mandiri energi. Serta memenangkan juara satu sebagai Desa Pelestari Hutan dan Konservasi Se-Bali dan Juara satu sebagai Desa Adaptasi dan Mitigasi Se-Bali. Seperti yang diungkapkan Perbekel Desa Kerta, Made Gunawan, pada wawancara hari Senin, 16 April, dinyatakan bahwa:

"Desa Kerta ini sudah banyak mendapat penghargaan sebagai Desa Iklim. Desa Iklim, kawasan hijaunya lebih luas dari pada kawasan non hijau. Tahun 2011 penghargaan dari kehutanan, tahun 2012 pernghargaan sebagai kampung iklim dan mandiri energi. Juara 1 Desa pelestari hutan dan konservasi. Juara 1 Desa abaptasi dan mitigasi"

Berdasarkan hal tersebut image desa Kerta sebagai desa iklim sudah ada dibenak masyarakat dan sudah diakui. Sehingga mudah untuk menyampaikan secara luas kepada masyarakat luas dan wisatawan.

\section{Analisis Target Audience}

Setelah melihat positioning, analisis target audiens bertujuan untuk menentukan calon wisatawan yang potensial untuk datang ke Desa Wisata Kerta. Setelah mengetahui calon wisatawan yang potensial dapat ditentukan isi pesan yang akan digunakan pada logo dan tagline. Calon wisatawan potensial dibagi berdasarkan segmentasi, yakni diantaranya:

\section{a. Geografis}

Segmentasi geografis yaitu masyarakat yang bertempat tinggal di wilayah perkotaan dan perdesaan. Umumnya masyarakat perkotaan cenderung membutuhkan tempat untuk menyegarkan 
pikiran setelah penat bekerja dan ingin mencari ketenangan serta pengalaman baru di desa. Dan masyarakat perdesaan ingin mengetahui bagaimana desa yang ada di daerah lain.

b. Demografis

1. Rentang Usia : $14-30$ tahun

2. Status : Perorangan atau individu dan group tour.

3. Jenis Kelamin: Laki-laki dan Perempuan

4. Pekerjaan : Siswa, Mahasiswa, tenaga pendidik

5. Agama: Semua kepercayaan dan agama

c. Psikografis

1. Menyukai panorama alam dan nuansa pedesaan

2. Suka terhadap hal- hal yang baru

d. Behaviouristik

1. Suka berpergian

2. Memanfaatkan gadget untuk aktifitas setiap hari

Konsep Perancangan Destination Branding Desa Wisata Kerta (Hartanto, 2016).

\section{Konsep Dasar}

Konsep dari perancangan Destination Branding Desa Wisata Kerta yakni untuk membentuk indentitas bagi Desa Wisata Kerta yang nantinya mempermudah orang dalam menggambarkan atau mempresentasikan Desa Wisata Kerta.

Dalam perancangannya, identitas Desa Wisata Kerta yang akan ditampilkan mengenai nuansa alam perdesaan yang menimbulkan perasaan senang bagi para wisatawan yang berkunjung ke Desa Wisata Kerta. Sehingga wisatawan yang datang memiliki kesan masing-masing yang membuat para wisatawan ingat tentang Desa Wisata Kerta dan menimbulkan kesan yang positif.

\section{Visual Branding}

Untuk membuat visual branding Desa Wisata Kerta yakni dengan meninjau positioning dari Desa Wisata Kerta. Positioning Desa Wisata Kerta tersebut adalah Desa Iklim dengan memunculkan nuansa perdesaan yang kental dengan pertanian, perkebunan dan hutan. Desa Wisata Kerta dikenal sebagai Desa Iklim karena luas kawasan hijaunya sebesar 1303.95 hektar setelah dikurangi dengan kawasan non hijau nya. Yakni kawasan hijau lebih luas dari kawasan non hijau. Desa Kerta telah mendapat banyak penghargaan Desa Iklim dari Kementrian Kehutanan tahun 2011. Tahun 2012 mendapat penghargaan sebagai Kampung Iklim dan Mandiri Energi.

3. Unsur ikonik

Berdasarkan tinjauan positioning dan unique selling preposition. Desa Kerta sebagai Desa Iklim di gambarkan dengan menggunakan beberapa komponen yang mewakili Desa Iklim yakni yang pertama adalah Bambu. Bambu dipilih karena bambu banyak terdapat di Desa Kerta dengan luas setengah dari 342.16 luas kawasan hutan. Bambu dominan berada di hutan rakyat. Selain itu Bambu mencerminkan tumbuhan yang berdasarkan filosofi agama Hindu dalam Konsep Tri Pramana tumbuhan termasuk dalam Eka Pramana (bayu) yaitu tumbuhan memiliki kemampuan untuk bertumbuh. Sehingga bisa dijadikan komponen logo desa wisata Kerta.

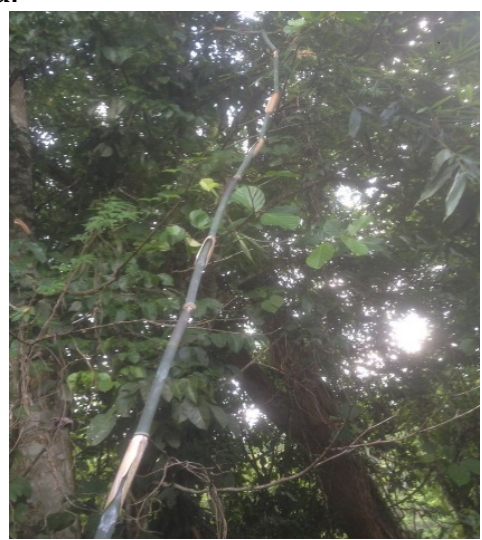

Gambar 4.2 Bambu

Sumber: Dokumentasi Gunawan, 2018

Komponen kedua yang mewakili Desa Iklim yakni ternak. Berdasarkan filosofi agama Hindu dalam konsep Tri Pramana. Hewan termasuk dalam kelompok Dwi Pramana. Kelompok hewan berkemapuan untuk tumbuh dan berkembang (bayu) serta kemampuan berbicara yang disebut (sabda). Hewan ternak yang dipilih untuk menjadi bahan perancangan logo Desa Wisata Kerta adalah Sapi. Sapi merupakan hewan suci dalam ajaran Hindu. Komponen yang ketiga yaitu manusia. Berdasarkan ajaran agama Hindu dalam konsep Tri Pramana, manusia memiliki tiga potensi dasar yakni tenaga (bayu), suara/Bahasa (sabda) dan kemampuan berpikir yang dikenal dengan idep. Manusia 
yang memiliki kemampuan untuk mengendalikan hewan dan tumbuhan.

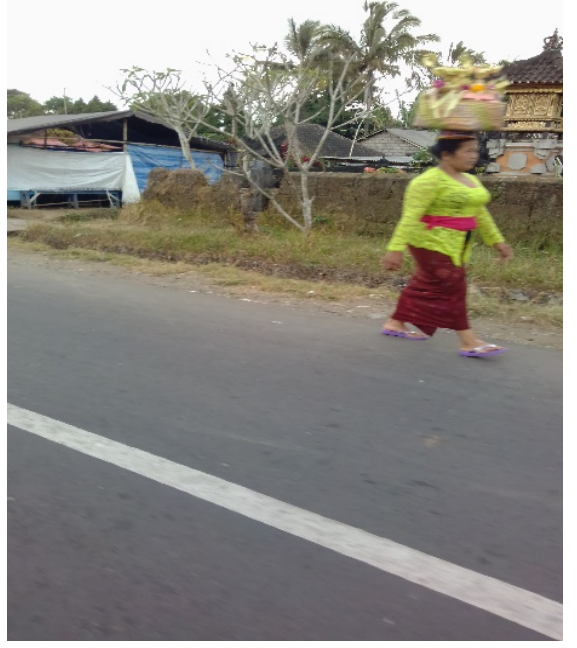

Gambar 4.3 Orang hendak menuju ke Pura

Sumber: Hasil Penelitian, 2018

Komponen ke empat yakni Pura. Pura banyak terdapat di Desa Wisata Kerta. Pura melambangkan hubungan manusia dengan Tuhan. Dengan adanya komponen Pura ini dapat menggambarkan bahwa agar selalu menjaga kelestarian alam dan tidak mengeksploitasi secara berlebihan.

\section{Proses Desain}

\section{Penggunaan warna dasar}

Penggunaan warna dasar pada branding Desa Wisata Kerta yakni menggunakan warna oranye dan hijau. Warna hijau melambangkan keindahan alam, keasrian dan kesuburan. Sedangkan warna oranye melambangkan nuansa kehangatan, kecerian dan rasa kekeluargaan. Sehingga warna oranye dan hijau memunculkan nuansa keasrian dan kehangatan.

\section{Logo}

Ide desain didapat dari kombinasi bentukan bambu, pura, ternak, dan manusia. Ide penggunaan empat karakter ini didasari bahwa Desa Kerta merupakan Desa Iklim sehingga komponen yang ada adalah bambu, ternak, manusia dan pura. Tiga Hal yang mewakili konsep Tri Pramana yakni bambu, ternak dan manusia. Berdasarkan filosofi agama Hindu yang terdapat konsep Tri Pramana, yaitu bayu, Sabda, Idep. Di mulai dari manusia yang memiliki ketiganya yakni bayu, sabda, dan idep. Idep atau pikiran hanya dimiliki manusia. Agar manusia bisa membedakan yang baik dengan yang buruk. Sedangkan binatang hanya memiliki kemampuan bayu dan sabda. Yakni berkembang dan mengeluarkan suara. Dan tumbuhan hanya memiliki bayu yakni tenaga untuk tumbuh. Sedangkan pura melambangkan hubungan manusia dengan tuhan. Sehingga ke-empat unsur tersebut dapat menciptakan Desa Kerta sebagai Desa Iklim.

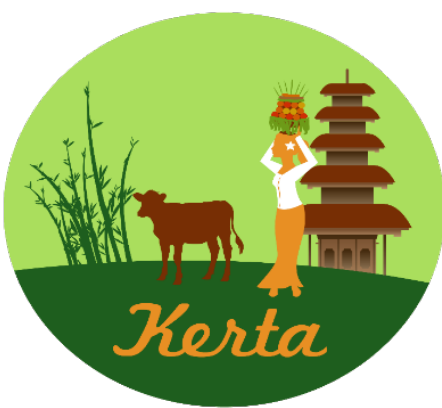

\section{Gambar 4.4 Logo Desa Wisata Kerta}

Arti logo:

1. Bambu: merupakan bambu yang dominan di Desa Kerta. Berdasarkan konsep Tri Pramana, tumbuhan termasuk dalam kelompok Eka Pramana (Bayu) yaitu tumbuhan dengan kemampuan untuk tumbuh.

2. Sapi: merupakan hewan ternak. Berdasarkan konsep Tri Pramana, Hewan termasuk dalam kelompok Dwi Pramana. Kelompok hewan dikenal memiliki dua potensi dasar yakni tumbuh dan berkembang (Bayu) serta kemampuan berbicara yang disebut (Sabda).

3. Manusia: Berdasarkan konsep Tri Pramana, manusia memiliki tiga potensi dasar yakni tenaga (bayu), suara/Bahasa (sabda) dan kemampuan berpikir yang dikenal dengan idep.

4. Pura: melambangkan hubungan manusia dengan Tuhan. Hal ini berkaitan dengan kondisi alam yang diciptakan oleh Tuhan dan dikelola oleh manusia.

5. Tulisan "KERTA" berwarna orange: dipilih karena melambangkan pengaruh berkemauan keras dan penuh semangat, energi, keseimbangan, kehangatan.

6. Bentuk Lingkaran: Lingkaran tidak memiliki awalan dan akhiran. Lingkaran berarti melindungi, memberikan 
pertahanan dan membatasi apa yang ada didalam dan menjaga hal-hal lain tetap diluar.

7. Warna hijau tua melambangkan hutan yang sangat lebat dan berkaitan dengan ketenangan.

8. Warna Hijau muda: melambangkan warna daun dan rumput juga bisa menyegarkan suasana hati.

\section{Tagline Desa Wisata Kerta}

Tagline yang digunakan untuk Desa Wisata Kerta adalah"Green Paradise". Tagline ini menggambarkan tentang kawasan hijau di Desa Kerta yang banyak terdapat berbagai potensi. Potensi yang ada di Desa Kerta terdiri dari potensi alam, budaya serta buatan. Desa ini digambarkan sebagai surga untuk dikunjungi oleh wisatawan, karena banyaknya potensi yang dapat ditemui di Desa Kerta.

\section{PENUTUP}

Perancangan destination branding Desa Wisata Kerta menunjukkan bahwa brand dari Desa Wisata Kerta adalah Desa Iklim. Desa Iklim dipilih menjadi brand Desa Wisata Kerta dikarenakan Desa Kerta sudah banyak mendapatkan penghargaan sebagai Desa Iklim. Desain logo Desa Wisata Kerta sebagai Desa Iklim digambarkan dengan empat komponen yakni bambu, sapi, manusia dan pura. Bambu, sapi dan manusia diambil berdasarkan filosofi ajaran Hindu yakni dari konsep Tri Pramana. Sedangkan pura melambangkan hubungan manusia dengan tuhan. Serta Tagline yang dihasilkan adalah " Green Paradise" yang artinya menggambarkan tentang kawasan hijau di Desa Kerta yang banyak potensi alam. Digambarkan sebagai surga untuk dikunjungi wisatawan.

Saran yang dapat diberikan kepada masyarakat agar lebih mengerti tentang Destination branding sehingga masyarakat lebih memahami image mereka sebagai desa wisata. Dan kepada pihak pengelola Desa Wisata Kerta lebih meningkatkan sosialisasi kepada masyarakat mengenai brand desa wisata Kerta. Serta membangun Desa Kerta sesuai dengan image yang terkandung didalam brand yang dibentuk oleh pihak pengelola Desa Kerta dan peneliti agar dapat memberikan kesan yang baik dan memenuhi ekspetasi wisatawan yang datang berkunjung terhadap kondisi alam dan budaya yang ada di Desa Kerta.

\section{DAFTAR PUSTAKA}

Arida, Sukma dan Pujani. 2017 Kajian Penyusunan Kriteria-kriteria Desa Wisata Sebagai Instrumen Dasar Pengembangan Desa Wisata. Jurnal Analisis Pariwisata Vol. 17 No. 1

Gunawan, I Made.2016 Pengembangan Agrowisata Untuk Kemandirian Ekonomi Dan Pelestarian Budaya Di Desa Kerta, Payangan Gianyar. Jurnal Master Pariwisata (Jumpa). Universitas Udayana. ISSN 2502-8022.

Hamidi. 2008. Metode Penelitian Kualitatif. Malang: UMM Press

Hartanto, Deddi Duto, et al.2016 Perancangan Destination Branding Desa Wisata Bermi Kabupaten Probolinggo. Jurnal DKV Adiwarna, 1.8: 11

Kerta I wayan. 2017. Potensi Wisata Sejarah Di Banjar Margatengah. Diakses melalui http://kerta.desa.id/2017/11/15/potensiwisata-sejarah-di-banjar-margatengah/ pada hari Selasa, 28 November 2017.

Kotler, Philip dan Kevin Lane Keller., 2007, Manajemen Pemasaran, Edisi Kedua Belas, Jilid 1, Dialihbahasakan oleh Benjamin Molan, Jakarta: PT Indeks.

Majdi, U. 2007 Quranic Quotient. Jakarta: Qultum Media 